\title{
Involvement of long non-coding RNAs in beta cell failure at the onset of type 1 diabetes in NOD mice
}

\author{
Anna Motterle ${ }^{1}$ - Sonia Gattesco ${ }^{1}$ - Dorothée Caille ${ }^{2}$. \\ Paolo Meda ${ }^{2} \cdot$ Romano Regazzi $^{1}$
}

Received: 12 December 2014 / Accepted: 6 May 2015 / Published online: 3 June 2015

(C) Springer-Verlag Berlin Heidelberg 2015

\begin{abstract}
Aims/hypothesis Exposure of pancreatic beta cells to cytokines released by islet-infiltrating immune cells induces alterations in gene expression, leading to impaired insulin secretion and apoptosis in the initial phases of type 1 diabetes. Long non-coding RNAs (lncRNAs) are a new class of transcripts participating in the development of many diseases. As little is known about their role in insulin-secreting cells, this study aimed to evaluate their contribution to beta cell dysfunction. Methods The expression of lncRNAs was determined by microarray in the MIN6 beta cell line exposed to proinflammatory cytokines. The changes induced by cytokines were further assessed by real-time PCR in islets of control and NOD mice. The involvement of selected lncRNAs modified by cytokines was assessed after their overexpression in MIN6 cells and primary islet cells.

Results MIN6 cells were found to express a large number of IncRNAs, many of which were modified by cytokine treatment. The changes in the level of selected lncRNAs were confirmed in mouse islets and an increase in these lncRNAs was also seen in prediabetic NOD mice. Overexpression of these lncRNAs in MIN6 and mouse islet cells, either alone or
\end{abstract}

Electronic supplementary material The online version of this article (doi:10.1007/s00125-015-3641-5) contains peer-reviewed but unedited supplementary material, which is available to authorised users.

Romano Regazzi

Romano.Regazzi@unil.ch

1 Department of Fundamental Neurosciences, Faculty of Biology and Medicine, University of Lausanne, Rue du Bugnon 9, 1005 Lausanne, Switzerland

2 Department of Cell Physiology and Metabolism, School of Medicine, University of Geneva, Geneva, Switzerland in combination with cytokines, favoured beta cell apoptosis without affecting insulin production or secretion. Furthermore, overexpression of IncRNA-1 promoted nuclear translocation of nuclear factor of $\mathrm{k}$ light polypeptide gene enhancer in B cells 1 (NF-kB).

Conclusions/interpretation Our study shows that lncRNAs are modulated during the development of type 1 diabetes in NOD mice, and that their overexpression sensitises beta cells to apoptosis, probably contributing to their failure during the initial phases of the disease.

Keywords Apoptosis - Beta cell · Cytokines - Diabetes · Islet $\cdot$ lncRNAs $\cdot$ Long non-coding RNAs

$\begin{array}{ll}\text { Abbreviations } \\ \text { ER } & \text { Endoplasmic reticulum } \\ \text { GFP } & \text { Green flourescent protein } \\ \text { lncRNA } & \text { Long non-coding RNA } \\ \text { miRNA } & \text { MicroRNA } \\ \text { NF-kB } & \text { Nuclear factor of } \kappa \text { light polypeptide gene en- } \\ & \text { hancer in B cells } 1 \\ \text { Rela } & \text { NF- } \kappa \text { B subunit } p 65 \\ \text { SCID } & \text { Severe combined immunodeficiency }\end{array}$

\section{Introduction}

Fine-tuning of insulin release from beta cells is essential to maintain blood glucose homeostasis. Type 1 diabetes is an autoimmune disease characterised by progressive infiltration of pancreatic islets by mononuclear cells, an inflammatory process called insulitis which leads to gradual destruction of beta cells [1]. During the initial phases of the disease, beta cells are chronically exposed to cytokines and other pro-apoptotic mediators, released 
by the immune cells infiltrating the islets of Langerhans and by the islet cells themselves [1]. Prolonged exposure to proinflammatory cytokines such as IL- $1 \beta$, TNF- $\alpha$ and IFN- $\gamma$ has deleterious effects on specialised beta cell functions, which leads to a decreased capacity to produce and release insulin in response to secretagogues, and ultimately to beta cell loss by apoptosis [1-4]. A deeper understanding of the mechanisms occurring during this inflammatory process is of paramount importance to identify new strategies for preventing and treating the disease.

Chronic exposure of beta cells to cytokines is known to modulate the expression of many genes, resulting in severe impairment of key signalling pathways [5-7]. Previous studies focused mainly on protein-coding genes, giving minor attention to a newly identified set of regulatory factors, the non-coding RNAs. In the context of diabetes, the most studied non-coding RNAs are the microRNAs (miRNAs) [8]. These molecules, which are important controllers of gene networks, are critical regulators of specialised beta cell functions [8] and are involved in beta cell damage during the development of type 1 diabetes $[9,10]$. In addition to miRNAs, recent transcriptome analysis has identified another class of functional molecules, the long non-coding RNAs (lncRNAs) [11-13]. Although the role of lncRNAs remains largely unknown, members of this RNA family have been involved in diverse gene-regulatory mechanisms such as transcription, imprinting, splicing, protein degradation and epigenetic marks on chromatin [14-19], and their dysregulation has been implicated in many human diseases [20, 21]. Little is known about the role of IncRNAs in the maintenance of beta cell activities and there are no data regarding the possible contribution of these molecules to the development of type 1 diabetes.

The aim of this project was to identify the lncRNAs that are differentially expressed under pathophysiological conditions favouring the development of type 1 diabetes, and to study their possible involvement in cytokine-mediated beta cell damage. We found that proinflammatory cytokines induce considerable changes in the transcriptional landscape of lncRNAs, some of which were also confirmed in islets of prediabetic NOD mice, a well-known model of type 1 diabetes [22]. Studies on the beta cell line MIN6 and in dissociated islet cells showed that overexpression of a selected subset of lncRNAs, either alone or in combination with cytokines, promotes beta cell apoptosis. In this study, we show for the first time that IncRNAs are modulated by proinflammatory cytokines and contribute to beta cell demise during the initial phases of murine type 1 diabetes.

\section{Methods}

Chemicals Recombinant mouse IL- $1 \beta$, hexadimethrine bromide, collagenase and Histopaque 1119 and 1077 were purchased from Sigma-Aldrich (St Louis, MO, USA). Recombinant mouse TNF- $\alpha$ was purchased from Enzo Life Sciences (Farmingdale, NY, USA), and recombinant mouse
IFN- $\gamma$ from R\&D Systems (Minneapolis, MN, USA). Hoechst dye 33342 was from Invitrogen (Basel, Switzerland).

Isolation, culture and dissociation of primary islet cells Mouse pancreatic islets were isolated from female NOD mice (Jackson Laboratory, Bar Harbor, ME, USA), male NOD severe combined immunodeficiency (SCID) mice (Janvier Labs, Le Genest-Saint-Isle, France) and C57BL/6 mice (13-14 weeks old; Charles River Laboratories, L'Arbresle, France). All animal procedures were performed in accordance with the National Institutes of Health guidelines and protocols were approved by the Swiss research council and veterinary offices. Mice islets were isolated by collagenase digestion [23] of the pancreas followed by Histopaque density gradient separation. Details about islet handling are provided in electronic supplementary material (ESM) Methods.

MIN6B1 cell culture The murine insulin-secreting cell line MIN6B1 [24] was cultured in DMEM-Glutamax medium (Invitrogen), supplemented with 15\% (vol./vol.) FCS, $50 \mu \mathrm{g} / \mathrm{ml}$ streptomycin, $50 \mathrm{U} / \mathrm{ml}$ penicillin (Invitrogen) and $70 \mu \mathrm{mol} / \mathrm{l} \beta$-mercaptoethanol (Sigma). Cells were seeded at a density of $10^{5} / \mathrm{cm}^{2}$ for insulin secretion and RNA isolation, and at $5 \times 10^{4} / \mathrm{cm}^{2}$ for cell death measurements.

Microarray profiling Total RNA was isolated with the RNeasy kit (Qiagen, Basel, Switzerland) from MIN6 cells treated with $0.1 \mathrm{ng} / \mathrm{ml} \mathrm{IL-1} \beta, 10 \mathrm{ng} / \mathrm{ml} \mathrm{TNF}-\alpha$ and $30 \mathrm{ng} / \mathrm{ml}$ IFN- $\gamma$ for $24 \mathrm{~h}$. Global mRNA and lncRNA expression profiling using the Mouse LncRNA Array v2.0 and data analysis were carried out by Arraystar (Rockville, MD, USA). Differentially expressed lncRNAs and mRNAs were identified through Volcano Plot filtering (fold change $\geq 1.5, p \leq 0.05$ ).

Measurement of IncRNA expression Total RNA was isolated using the RNeasy kit followed by DNase treatment on column (Qiagen). RNA, $1 \mu \mathrm{g}$, was reverse transcribed using Moloney murine leukaemia virus (M-MLV) reverse transcriptase, RNAse H minus (Promega, Madison, WI, USA). Realtimex PCR was performed using iQ SYBR Green mix and samples were amplified using the CFX Connect Real-Time PCR System (Biorad, Hercules, CA, USA). The full primer list is presented in ESM Table 1.

Transfection and lentiviral infection MIN6B1 cells were transfected with a control pcDNA3 plasmid or with the same plasmid containing the sequences to translate the lncRNAs ( pcDNA3 3 ncRNA-1; pcDNA3 3 ncRNA-2, pcDNA3_lncRNA-3, pcDNA3_lncRNA-4), using Lipofectamine 2000 (Invitrogen). Plasmids containing the sequence of the lncRNA of interest or a $g f p$ mRNA were used to 
produce lentiviral vectors, as described [25]. Details of lentiviral manipulation are provided in ESM Methods.

Insulin secretion Insulin secretion from MIN6B1 cells transfected with the relevant plasmids for $48 \mathrm{~h}$ was carried out as previously described [10].

Assessment of cell death The percentage of apoptotic cells was determined by scoring the fraction of cells displaying pycnotic nuclei under fluorescence microscopy (AxioCam MRc5, Zeiss, Feldbach, Switzerland) after incubation with $1 \mu \mathrm{g} / \mathrm{ml}$ Hoechst dye. At least 500 cells were inspected for each condition.

NF- $K$ B nuclear translocation MIN6B1 cells were transfected with a plasmid expressing a green fluorescent protein (GFP)-tagged form of the human nuclear factor of $k$ light polypeptide gene enhancer in B cells 1 (NF- $\mathrm{kB}$ ) subunit p65 (Rela) and/or the plasmid expressing the lncRNA of choice. At $24 \mathrm{~h}$ after transfection, the cells were treated with the indicated cytokines for $3 \mathrm{~h}$, fixed and mounted on a cover slip for microscopic examination. The fraction of cells displaying nuclear localisation of p 65 was calculated after analysing around 1,500 cells for each condition.

Statistical analysis Data are presented as mean \pm SEM. Statistical differences were assessed by two-tailed paired Student's $t$ test when only two sets of data were present (Figs 2 and 6a-d) or by one-way ANOVA followed by Tukey's post hoc test, with a discriminating $p$ value of 0.05 (GraphPad Prism 5, San Diego, California, USA).

\section{Results}

To investigate the possible contribution of lncRNAs to beta cell dysfunction, MIN6 cells were incubated for $24 \mathrm{~h}$ with a mix of cytokines. The expression profile of protein-coding genes and of previously annotated lncRNAs was determined by microarray analysis. In agreement with previous reports in INS1E cells $[5,26]$, rat beta cells [6], mice islets [27] and human islets [7], cytokines modified the expression of numerous protein-coding genes involved in inflammatory responses (i.e. Ccl2, Cxcl1, Cxcl2, Icam1, IL15), IFN- $\gamma$ signalling (i.e. Irf1, Irf7, Igtp, Stat1, Stat2, Stat3, Stat4 and Jak3), NF-кB regulation (i.e. Nfkbia, $N f k b 2, N f k b i z$ ), endoplasmic reticulum (ER) stress and apoptosis (Atf3, Atf6, Atf2, Bid, Bik1, Casp1, Casp 4, Chop [also known as Ddit3]) and others (ESM Table 2). Hierarchical clustering showed a distinguishable lncRNA expression profile in the two groups of samples obtained from MIN6 cells (Fig. 1a). Control MIN6 cells expressed 18,066 of the 31,000 transcripts included in the array. On treatment with cytokines, 467 transcripts were upregulated and 219 were downregulated (Fig. 1b and ESM Table 3). Under control conditions, the average raw expression level of IncRNAs was about three times lower than that of protein-coding genes and six times lower than that observed after exposure to cytokines (data not shown). Four upregulated IncRNAs, which for simplicity will be hereafter referred as IncRNA-1, $-2,-3$ and -4 , were selected for further analysis. LncRNA-1, -2 and -3 were chosen because they displayed the most significant expression changes. LncRNA-4 was selected because it is intergenic and the full sequence was available. The fold changes of these lncRNAs in response to cytokine treatment, and their genomic location are displayed in Fig. 1c.

The increase in the four IncRNAs upregulated by cytokines was confirmed by quantitative real-time PCR (Fig. 2a-d). These lncRNAs were almost undetectable in control MIN6 cells, and after incubation with cytokines for $24 \mathrm{~h}$ the expression of IncRNA-1, -2, -3 and -4 increased by 1,072-, 148-, 209- and 3.8-fold, respectively (Fig. 2a-d). Similar results were observed in islets isolated from $\mathrm{C} 57 \mathrm{BL} / 6 \mathrm{~N}$ mice incubated with the same cytokines for $24 \mathrm{~h}$, with IncRNA-1, $-2,-3$ and -4 being upregulated 520-, 26-, 36- and 3.6-fold, respectively (Fig. 2e-h). Similar data were obtained when the data were normalised using 18S ribosomal RNA instead of Gapdh (ESM Fig. 1). These changes appeared to be specifically induced by cytokines, as they were not observed when MIN6 cells were incubated with palmitate or with the glucagon-like peptide-1 (GLP1) analogue exendin-4 (ESM Fig. 2). The expression of these lncRNAs increased rapidly after treatment with cytokines; the induction of IncRNA-1 and -2 was significant after $6 \mathrm{~h}$ treatment, whereas that of IncRNA- 3 and -4 was already significant after $2 \mathrm{~h}$ treatment (Fig. 3). Incubation of MIN6 cells with different combinations of proinflammatory cytokines showed that IFN- $\gamma$ alone was sufficient to induce the expression of IncRNA-1, IncRNA-3 and IncRNA-4 (Fig. 4). The changes seen for IncRNA-2 reached statistical significance only in the presence of a mix of cytokines (Fig. 4).

Subsequently, we studied whether changes in the level of islet lncRNAs precede the development of type 1 diabetes in NOD mice. Although a minor infiltration of lymphocytes has been reported as early as at 4 weeks of age, in these mice periinsulitis (a leucocytic lesion on the pole of the islet) becomes evident between 6 and 8 weeks and by week 12 is present in the majority of islets $[22,28]$. In this study, we used prediabetic female NOD mice displaying normal blood glucose levels and we isolated the islets at 4,8 and 13 weeks of age. We found that the levels of lncRNA-1 and lncRNA-2 were significantly higher in the islets of 8 and 13 week old mice than in those of 4 week old mice. LncRNA-3 expression was also higher in the islets of 8 week old mice compared with 4 week old mice, while lncRNA-4 did not reach statistical significance (Fig. 5). The expression of these lncRNAs was not modified in NOD SCID mice that do not develop type 1 
Fig. 1 (a) Hierarchical clustering of the samples analysed by microarray. The dendrogram shows the relationship between the expression of control samples (3 replicates) and samples exposed for $24 \mathrm{~h}$ to $0.1 \mathrm{ng} / \mathrm{ml}$ IL-1 $\beta, 10 \mathrm{ng} / \mathrm{ml} \mathrm{TNF-} \alpha$ and $30 \mathrm{ng} / \mathrm{ml}$ IFN- $\gamma$ (3 replicates). Red, high expression; blue, low expression. (b) Volcano plot summarising the results obtained by microarray, in which control and cytokine-exposed MIN6 cells are compared. Significantly up- or downregulated transcripts are in red. (c) Studied lncRNAs with fold changes, $p$ values and genomic locations. Cyt Mix, cytokine mix; Ctrl, control a

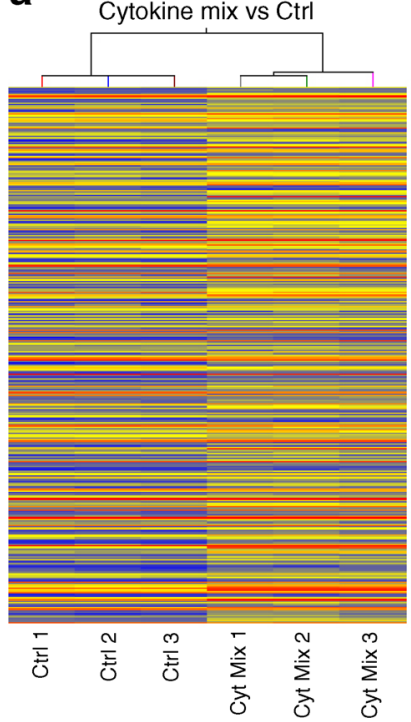

b

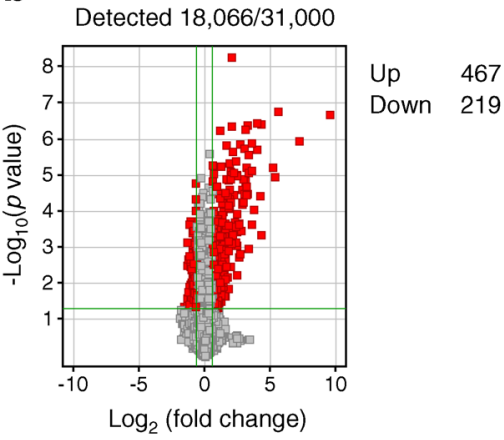

\section{C}

IncRNA Transcript Fold change $p$ value Genomic location IncRNA-1 gm5970 $766.9 \quad 1.98 \times 10^{-7}$ chr18:60380496-60381712 \begin{tabular}{l|l|l|l|l}
\hline IncRNA-2 Al451557 & 146.4 & $1.10 \times 10^{-6}$ & chr8:97048966-97051168
\end{tabular} IncRNA-3 BC002288 $\quad 42.1 \quad 1.07 \times 10^{-5}$ chr2:121973452-121975096 \begin{tabular}{l|l|l|l}
\hline IncRNA-4 gm16675 & 5.4 & $0.89 \times 10^{-3}$ & chr:47816325-47824869
\end{tabular}
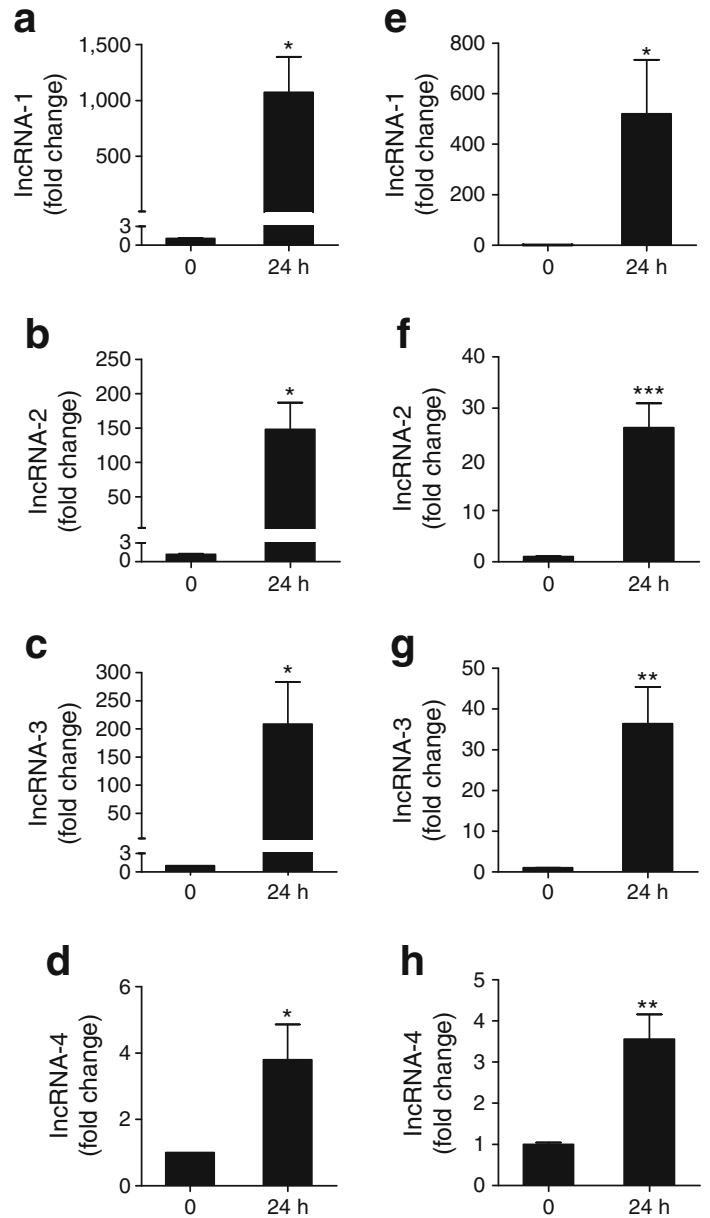

h

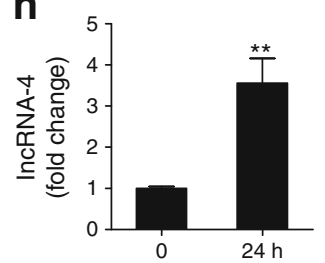

Fig. 2 The four lncRNAs are induced by proinflammatory cytokines. MIN6 cells (a-d) and mouse islets (e-h) were incubated in the absence (0) or presence of $0.1 \mathrm{ng} / \mathrm{ml} \mathrm{IL-} 1 \beta, 10 \mathrm{ng} / \mathrm{ml} \mathrm{TNF}-\alpha$ and $30 \mathrm{ng} / \mathrm{ml} \mathrm{IFN}-\gamma$ ( $24 \mathrm{~h}$ incubation). The expression levels were measured by real-time PCR and normalised to those of Gapdh. The results are means \pm SEM of three to six independent experiments. ${ }^{*} p<0.05,{ }^{* *} p<0.01$ and ${ }^{* * *} p<0.001$ vs control

diabetes (ESM Fig. 3), demonstrating that their upregulation is linked to the autoimmune reaction.

We then tested whether the changes in the expression of these lncRNAs affect specific beta cell functions. Overexpression of the four lncRNAs in MIN6 cells (ESM Fig. 4) did not modify the insulin mRNA level (ESM Fig. 5), the insulin content (Fig. 6a-d) or insulin release (Fig. 6e-h). Prolonged exposure of beta cells to cytokines sensitises them to apoptosis $[1,3]$. The expression of the four lncRNAs is controlled by cytokines and rises concomitantly with the increase in insulitis (Fig. 5), suggesting that they may be involved in the events causing beta cell failure. Therefore, we investigated whether the modulation of these lncRNAs affects beta cell survival. We found that overexpression of lncRNA-3 and lncRNA-4 in MIN6 cells is sufficient to increase the number of apoptotic cells, and that this effect is

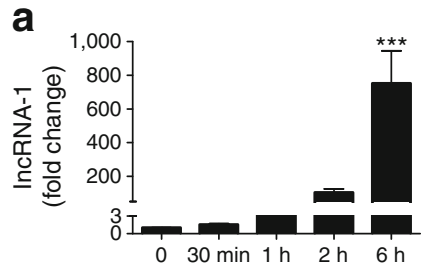

C

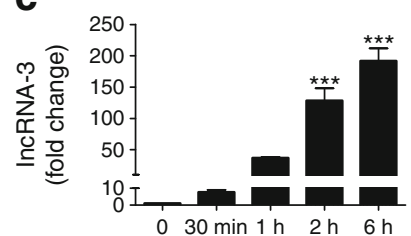

b

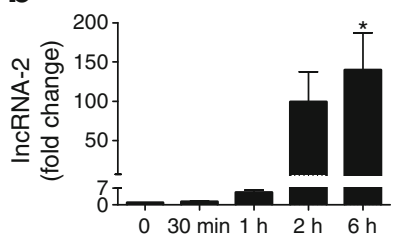

d

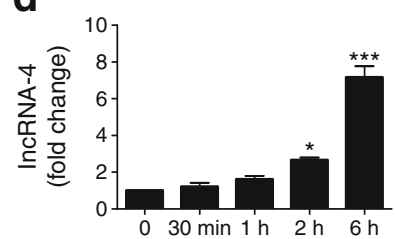

Fig. 3 Time course of the induction of the lncRNAs. MIN6 cells were incubated for the indicated periods with $0.1 \mathrm{ng} / \mathrm{ml} \mathrm{IL}-1 \beta, 10 \mathrm{ng} / \mathrm{ml} \mathrm{TNF}-\alpha$ and $30 \mathrm{ng} / \mathrm{ml} \mathrm{IFN-} \gamma(\mathbf{a}-\mathbf{d})$. The expression was measured by real-time PCR and normalised to that of Gapdh. The results are means \pm SEM of three independent experiments. ${ }^{*} p<0.05$ and ${ }^{* * * *} p<0.001$ vs the control at $0 \mathrm{~h}$ 
Fig. 4 IFN- $\gamma$ is sufficient to induce the expression of the lncRNAs. MIN6 cells were incubated in the presence or absence of different cytokines at the concentrations given in the previous figures $(\mathbf{a}-\mathbf{d})$. The expression was measured by realtime PCR and normalised to that of Gapdh. The results shown are means \pm SEM of three independent experiments. ${ }^{* *} p<0.01$ and ${ }^{* * *} p<0.001$ vs control. Ctrl, control a

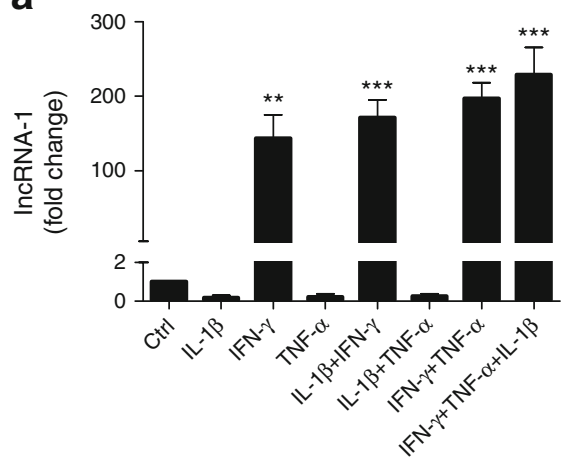

b
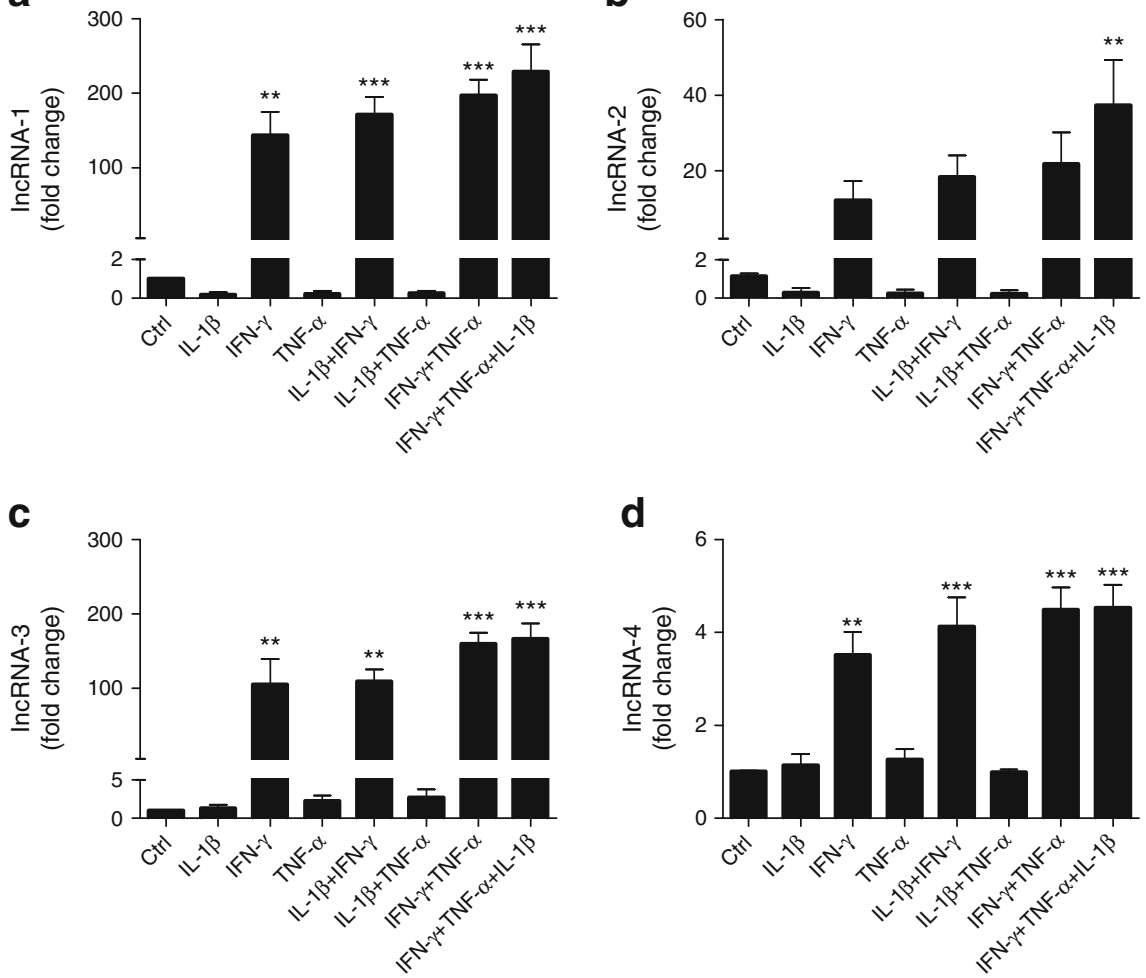

d

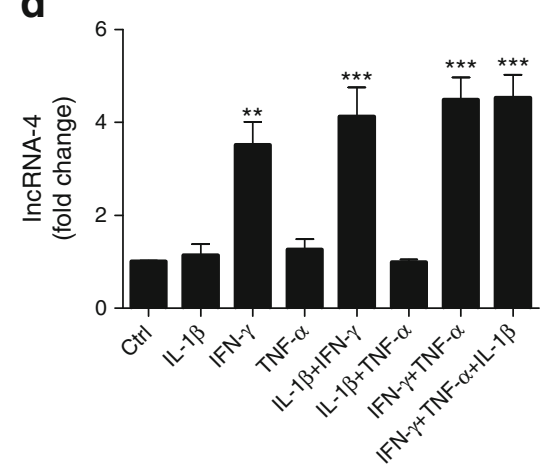

not increased in the presence of cytokines (Fig. 7c, d). In contrast, overexpression of either IncRNA-1 or lncRNA-2 alone did not modify the proportion of apoptotic cells. However, the overexpression of these lncRNAs increased apoptosis when the cells were concomitantly incubated with low doses of IL-1 $\beta$ or TNF- $\alpha$, which alone did not affect cell survival (Fig. 7a, b), suggesting that the combination of both signals is necessary to trigger apoptosis. Similar results were
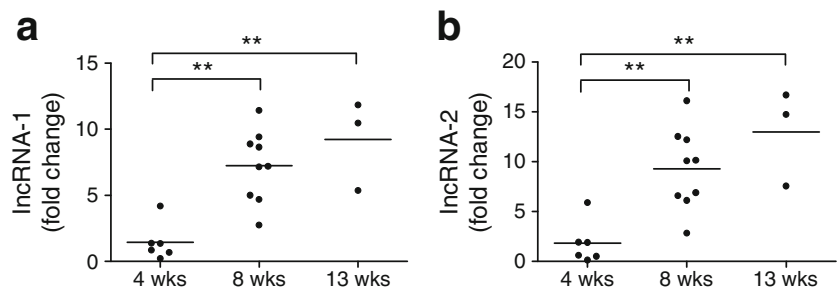

C

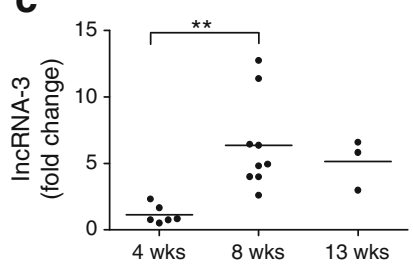

d

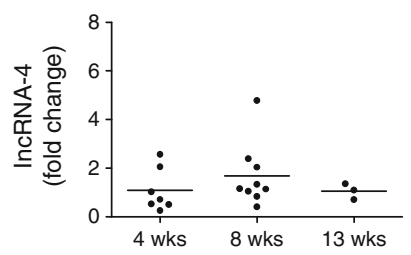

Fig. 5 The expression of lncRNA-1, -2 and -3 increases with insulitis in islets of NOD mice. Islets were isolated from female mice aged 4,8 and 13 weeks. The level of the four $\operatorname{lncRNAs}$ was measured by real-time PCR and normalised to that of $\operatorname{Gapdh}(\mathbf{a}-\mathbf{d}) .{ }^{* *} p<0.01$ vs the levels measured in 4-week-old animals. Wks, weeks obtained in mice islets (Fig. 7e, f), transduced with lentiviral vectors (ESM Fig. 6). We then investigated whether the overexpression of these lncRNAs, either alone or in combination with IL-1 $\beta$, modifies the level of some members of the $\mathrm{Bcl}-2$ family (Bik1 and Bid) or of the downstream ER-stress-related genes Chop and Atf3. No significant effect was observed on any of these genes (ESM Fig. 7).

Although basal NF- $\mathrm{KB}$ activity is required for normal insulin release [29], induction of the NF- $\kappa$ B pathway plays a central role in cytokine-induced apoptosis [30]. Translocation of NF- $\kappa \mathrm{B}$ to the nucleus is one of the initial events occurring shortly after exposure to IL-1 $\beta$ [31]. In view of the potential crosstalk with the NF- $\kappa$ B pathway, we transfected MIN6 cells with a GFP-tagged form of $\mathrm{p} 65$, one of the NF- $\mathrm{BB}$ subunits in the predominant dimers (p65/p65 and p65/p50) found in IL$1 \beta$-exposed beta cells [32], and we monitored its translocation to the nucleus on overexpression of each of the four lncRNAs. We found that incubation of cells in the presence of low doses of IL-1 $\beta(0.1 \mathrm{ng} / \mathrm{ml})$ or IFN- $\gamma(30 \mathrm{ng} / \mathrm{ml})$ does not affect the intracellular distribution of NF-KB (Fig. 8, ESM Fig. 8). In contrast, incubation with higher doses of IL-1 $\beta(10 \mathrm{ng} / \mathrm{ml})$ or IFN- $\gamma(300 \mathrm{ng} / \mathrm{ml})$ led to an increase in the fraction of cells in which NF- $\mathrm{BB}$ is localised in the nucleus. Of the four lncRNAs studied, only overexpression of lncRNA-1 mimicked the effect of high doses of IL- $1 \beta$ or IFN- $\gamma$, and increased the fraction of cells in which p65 is localised to the nucleus (Fig. 8). This effect was not further potentiated by exposing the cells to IL-1 $\beta$ (Fig. 8). 

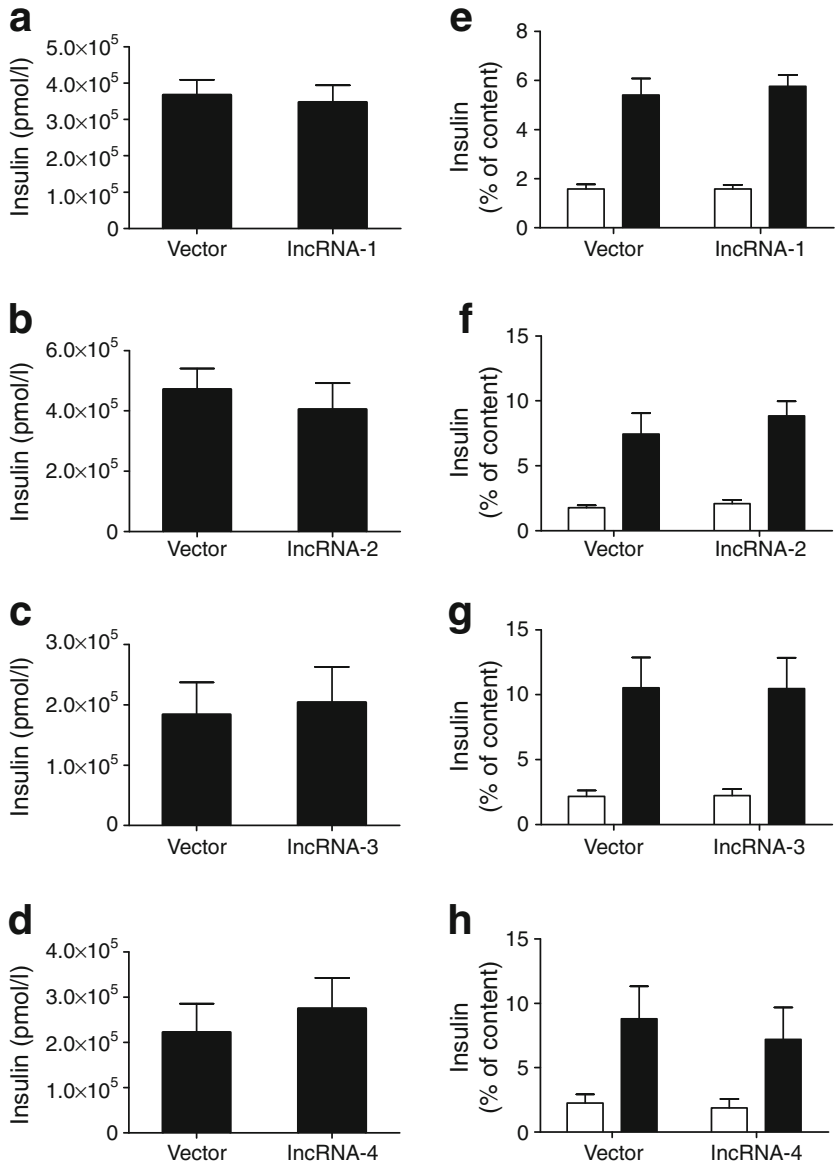

Fig. 6 Overexpression of the lncRNAs does not affect insulin content or secretion. MIN6 cells were transfected for $48 \mathrm{~h}$ with an empty plasmid (vector) or a plasmid enabling the transcription of an individual lncRNA. The cellular insulin content was measured by ELISA (a-d). To test their secretory properties, the cells were incubated with 2 or $20 \mathrm{mmol} / \mathrm{l}$ glucose for $45 \mathrm{~min}$. Basal and glucose-induced insulin release were assessed by ELISA (e-h). The results represent means \pm SEM of three to six independent experiments

\section{Discussion}

Type 1 diabetes is characterised by progressive islet infiltration by immune cells releasing cytokines and other proapoptotic mediators that contribute to beta cell death during the initial phases of the disease [1]. In diabetes-prone NOD mice beta cell apoptosis precedes substantial lymphocytic infiltration [33, 34], supporting the notion that inflammatory mediators released by infiltrating cells play a major role in beta cell death. Accordingly, chronic exposure to proinflammatory cytokines has detrimental effects on specialised beta cell functions [1-4] and affects the expression of proteincoding genes and of small non-coding RNAs [5-7]. We previously showed that changes in the level of miRNAs can affect the secretory capacities of beta cells and their sensitivity to apoptosis $[9,10]$. Here, we not only demonstrate that incubation of MIN6 cells with a mix of T helper 1 cytokines results in considerable changes in the expression of protein-coding
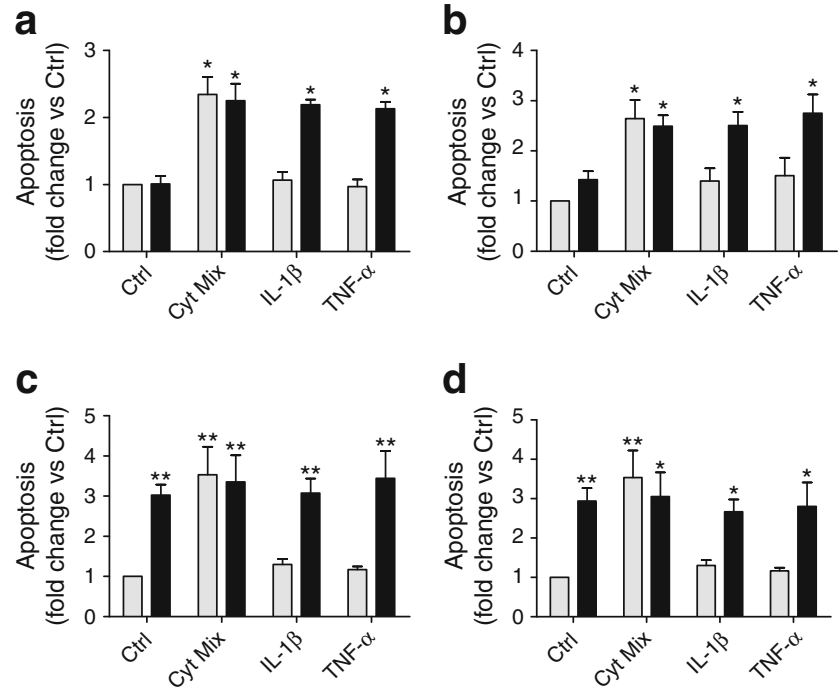

d
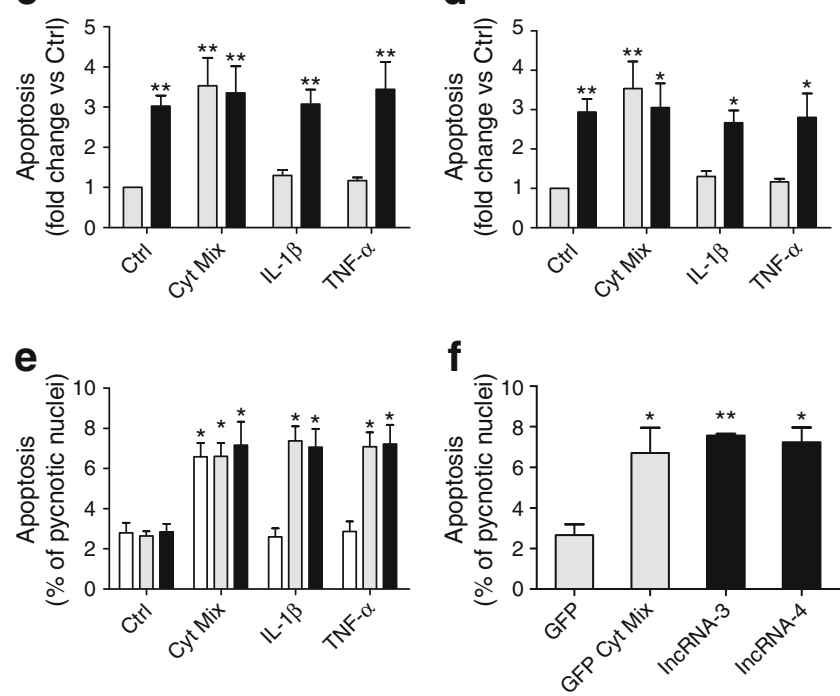

Fig. 7 Overexpression of the lncRNAs triggers apoptosis. (a-d) MIN6 cells were transfected with a control plasmid (vector; grey) or with plasmids overexpressing lncRNA-1 (a); lncRNA-2 (b); lncRNA-3 (c) or IncRNA-4 (d) (black). After $24 \mathrm{~h}$, the cells were incubated for another $24 \mathrm{~h}$ with or without single cytokines or a mix of the three at a concentration of $0.1 \mathrm{ng} / \mathrm{ml} \mathrm{IL-1} \beta, 10 \mathrm{ng} / \mathrm{ml} \mathrm{TNF}-\alpha$ and $30 \mathrm{ng} / \mathrm{ml} \mathrm{IFN-} \gamma$. Dispersed mouse islet cells were transduced with a control lentiviral vector expressing GFP or a vector expressing the lncRNA of interest (e, GFP in white, lncRNA-1 in grey and lncRNA-2 in black; $\mathbf{f}$, as indicated). Incubation with cytokines was performed as described above. The proportion of cells showing pycnotic nuclei was scored. Fold changes were calculated by dividing the values by the percentage of pycnotic nuclei observed in controls $(\mathbf{a}-\mathbf{d})$. The results are the means \pm SEM of four to six independent experiments. ${ }^{*} p<0.05$ and ${ }^{* *} p<0.01$ vs control. Ctrl, control; Cyt Mix, cytokine mix

genes involved in inflammatory responses, IFN- $\gamma$ signalling, NF- $\mathrm{KB}$ regulation, ER stress and apoptosis similar to those shown in previous reports $[5-7,26,27]$ but we also reveal for the first time that it causes major modifications in IncRNA expression. Despite extensive research, the role of the majority of these transcripts is still unknown and no information is available regarding their contribution to the maintenance of beta cell function and the development of type 1 diabetes. We found that MIN6 cells express many previously annotated lncRNAs, and that a considerable fraction of these transcripts are modulated in the presence of proinflammatory cytokines. In agreement with previous studies $[35,36]$, we found that the average levels of IncRNA expression in MIN6 cells were lower than those of protein-coding genes. 

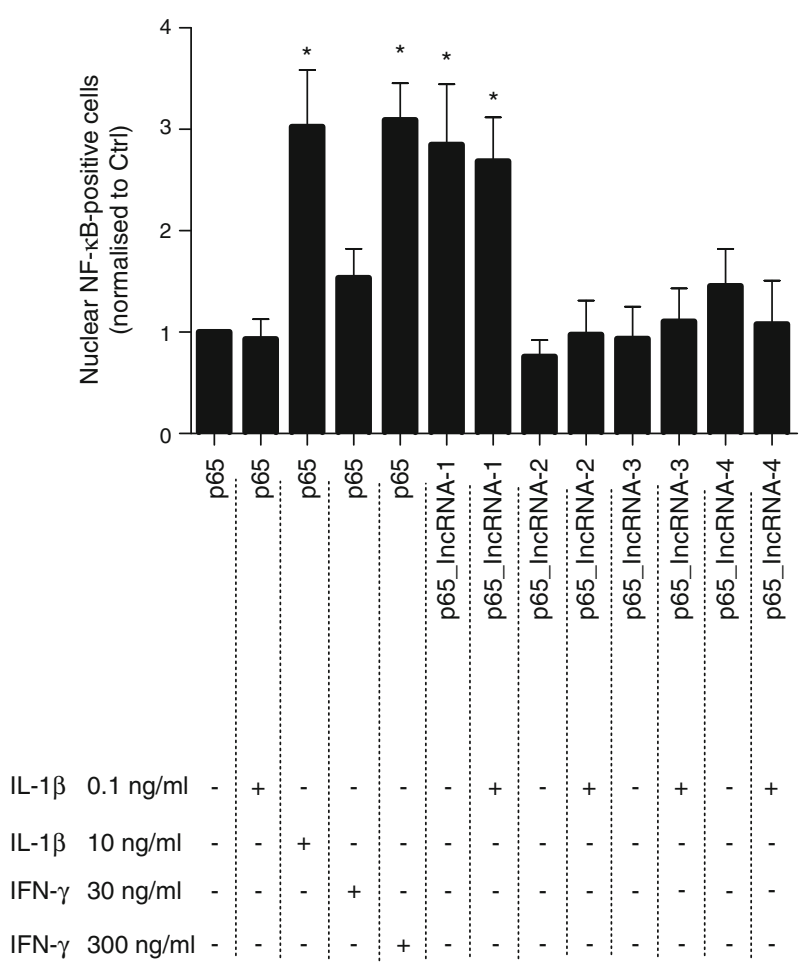

Fig. 8 Overexpression of lncRNA-1 induces the nuclear translocation of NF-KB. MIN6 cells were transfected for $24 \mathrm{~h}$ with a plasmid expressing GFP-tagged p65 (Rela). They were then exposed for $3 \mathrm{~h}$ to the indicated cytokines before fixation and fluorescence microscopy analysis. The number of cells displaying nuclear NF-kB localisation were scored. Data were normalised to the values of control p65 with no cytokine exposure. The results shown represent means \pm SEM of six independent experiments. ${ }^{*} p<0.05$ vs the control value (p65, no cytokine exposure). Ctrl, control

We focused on four lncRNAs and demonstrated that the proinflammatory cytokines modulate their expression in mouse islets. IFN- $\gamma$ was sufficient to induce the expression of these lncRNAs. Interestingly, in NOD mice during the initial phases of the disease, the islet genes displaying the higher expression changes are all induced by IFNs [28]. The expression of the four tested lncRNAs is rapidly increased by cytokines, suggesting that these lncRNAs act early in the cascade of events activated by the inflammatory mediators, and culminating in cell death. This is not surprising as the expression of many protein-coding genes involved in beta cell apoptosis is already modified after $2 \mathrm{~h}$ exposure to cytokine $[5,26]$.

Subsequently, we investigated whether changes in the level of these $\operatorname{lncRNAs}$ precede the development of diabetes and we measured their expression in islets of normoglycaemic NOD mice of increasing age. We found that the levels of lncRNA-1, lncRNA-2 and lncRNA-3 increase with age, paralleling the development of insulitis in the early phases of the disease [22, 28]. This was not observed in NOD SCID mice, which are immunodeficient and do not develop diabetes, suggesting that the induction of these IncRNAs is a consequence of the autoimmune reaction. In NOD mice autoimmune destruction of beta cells is preceded by defective insulin secretion [37]. However, none of the IncRNAs investigated had an impact on insulin biosynthesis and release. As in NOD mice beta cell apoptosis precedes substantial lymphocytic infiltration [33, 34] and prolonged exposure to cytokines sensitises beta cells to apoptosis [1-4], we assessed whether the modulation of lncRNAs affects the survival of insulin-secreting cells. Indeed, overexpression of lncRNA-3 and lncRNA-4 was sufficient to increase apoptosis of MIN6 and mouse islet cells. In contrast, lncRNA1 and lncRNA-2 induced apoptosis only in cells concomitantly exposed to low doses of IL- $1 \beta$ or TNF- $\alpha$. This suggests that lncRNA-1 and -2 trigger apoptosis only when the beta cells receive a combination of signals generated by the activation of different inflammatory pathways. This is reminiscent of the events occurring in the initial phases of type 1 diabetes when beta cell death is believed to be elicited by prolonged exposure to a combination of inflammatory mediators, rather than to low doses of a single cytokine [38]. Cytokines modify the level of many genes belonging to the $B c l 2$ family $[6,39]$ and activate the ER stress response [40]. Overexpression of the four lncRNAs, alone or in combination with IL1- $\beta$, neither altered the expression of the pro-apoptotic $B c l 2$ family members $B i k 1$ and $B i d$, nor affected the levels of the downstream ER stress-related genes Chop and Atf3, suggesting that they may not operate through activation of these genes.

Stimulation of beta cells with either IL- $1 \beta$ or TNF- $\alpha$ results in the activation of NF-KB [41], a key regulator of gene networks controlling cytokine-induced beta cell dysfunction and death [30]. Indeed, inhibition of NF- $\mathrm{KB}$ activation in vitro by overexpression of inhibitory $\mathrm{KB}(\mathrm{I} \kappa \mathrm{B})$ protects beta cells against cytokine-induced apoptosis $[42,43]$. Furthermore, beta cell-specific NF-kB blockade in vivo prevents streptozotocin-induced diabetes development [44]. The translocation of NF- $\mathrm{KB}$ into the nucleus is one of the initial events occurring shortly after exposure to IL- $1 \beta$ or TNF- $\alpha$ [31]. In INS1E cells, IL-1 $\beta$ triggers a stronger induction of NF- $\mathrm{kB}$ target genes compared with TNF- $\alpha$, partly because it elicits an earlier translocation of NF- $\mathrm{kB}$ into the nucleus [31] and a more stable activation of this signalling pathway [32]. We found that lncRNA-1 promotes the translocation of p65 into the nucleus, mimicking the effects observed when the cells are exposed to high doses of IL- $1 \beta$ and IFN- $\gamma$. On overexpression of IncRNA-1, low doses of IL- $1 \beta$ are sufficient to induce apoptosis. Thus, sensitisation of beta cells overexpressing IncRNA-1 to apoptosis may at least in part be caused by NF-KB nuclear translocation. Our findings indicate a possible crosstalk of IFN- $\gamma$ with the NF- $\mathrm{kB}$ pathway in beta cells. IFN- $\gamma$ exerts its functions mainly through the Janus kinase (JAK)-signal transducer and activator of transcription (JAKSTAT) cascade [45], but accumulating evidence indicates that in some cell types IFN- $\gamma$ can also activate the NF- $\mathrm{kB}$ pathway $[46,47]$. The mechanisms through which the NF-kB pathway may mediate the actions of IFN- $\gamma$ remain largely unknown. 
Our data suggest that lncRNAs could provide a link between the two signalling cascades. Further studies will be needed to elucidate the precise mechanism through which lncRNA-1 induces the nuclear translocation of NF- $\mathrm{KB}$ and, in general, to understand the role of IncRNA-2, IncRNA-3 and IncRNA-4 in beta cell apoptosis.

Overall, our findings show that proinflammatory cytokines induce extensive changes in the expression of previously annotated lncRNAs. The study of four selected lncRNAs shows that the expression of these non-coding transcripts increases with the development of insulitis in NOD mice and that their modulation increases beta cell apoptosis, suggesting that they may contribute to cytokine-mediated beta cell dysfunction occurring during the initial phases of type 1 diabetes. The four lncRNAs investigated in this study are most probably not the only long non-coding transcripts contributing to beta cell demise. In fact, our data have highlighted dramatic changes in the level of many other lncRNAs elicited by cytokines and these inflammatory mediators may potentially also affect the expression of some of the recently described beta cell-specific mouse lncRNAs [48] that were not included in the array.

Future studies will not only need to elucidate the contribution of all these IncRNAs in the development of type 1 diabetes in mice but will also need to assess whether the same mechanism operates in humans. This promises to be a difficult task because, although the function of IncRNAs is likely to be maintained, the conservation of the sequence throughout species can be as little as $21 \%$, with exons being under less evolutionary constraint than in protein-coding genes [35, 49]. The genomic loci from which the four lncRNAs are generated produce a large number of partially overlapping transcripts and it was not possible to identify with certainty their human orthologues. New computational approaches based on the analysis of the secondary structure rather than on sequence conservation will be necessary to precisely identify the human transcripts corresponding to the lncRNAs investigated in this study.

Acknowledgements We would like to thank the group of C. Widmann for kindly providing the vector expressing Rela and Arraystar for the microarray service provided.

Funding This work was supported by the European Foundation for the Study of Diabetes and Lilly research fellowship (AM), by grants of the Swiss National Science Foundation (310030-146138 to RR and 310000141162 to PM) and by the Fondation Francophone pour la Recherche sur le Diabète (RR).

Duality of interest The authors declare that there is no duality of interest associated to this manuscript.

Contribution statement AM conceived the experiments, generated the research, analysed the data, wrote the manuscript and approved its final version. SG, DC and PM contributed to the acquisition of data, reviewed the manuscript and approved its final version. RR conceived the experiments, analysed the research data, wrote the manuscript and approved its final version. AM is responsible for the integrity of the work as a whole.

\section{References}

1. Eizirik DL, Colli ML, Ortis F (2009) The role of inflammation in insulitis and beta-cell loss in type 1 diabetes. Nat Rev Endocrinol 5: 219-226

2. Donath MY, Storling J, Berchtold LA, Billestrup N, MandrupPoulsen T (2008) Cytokines and beta-cell biology: from concept to clinical translation. Endocr Rev 29:334-350

3. Pipeleers D, Hoorens A, Marichal-Pipeleers M, van de Casteele M, Bouwens L, Ling Z (2001) Role of pancreatic beta-cells in the process of beta-cell death. Diabetes 50(Suppl 1):S52-S57

4. Kaminitz A, Stein J, Yaniv I, Askenasy N (2007) The vicious cycle of apoptotic beta-cell death in type 1 diabetes. Immunol Cell Biol $85: 582-589$

5. Kutlu B, Cardozo AK, Darville MI et al (2003) Discovery of gene networks regulating cytokine-induced dysfunction and apoptosis in insulin-producing INS-1 cells. Diabetes 52:2701-2719

6. Ortis F, Naamane N, Flamez D et al (2010) Cytokines interleukin1 beta and tumor necrosis factor-alpha regulate different transcriptional and alternative splicing networks in primary beta-cells. Diabetes 59:358-374

7. Eizirik DL, Sammeth M, Bouckenooghe T et al (2012) The human pancreatic islet transcriptome: expression of candidate genes for type 1 diabetes and the impact of pro-inflammatory cytokines. PLoS Genet 8:e1002552

8. Guay C, Jacovetti C, Nesca V, Motterle A, Tugay K, Regazzi R (2012) Emerging roles of non-coding RNAs in pancreatic beta-cell function and dysfunction. Diabetes Obes Metab 14(Suppl 3):12-21

9. Roggli E, Britan A, Gattesco S et al (2010) Involvement of microRNAs in the cytotoxic effects exerted by proinflammatory cytokines on pancreatic beta-cells. Diabetes 59:978-986

10. Roggli E, Gattesco S, Caille D et al (2012) Changes in microRNA expression contribute to pancreatic beta-cell dysfunction in prediabetic NOD mice. Diabetes 61:1742-1751

11. Carninci P, Kasukawa T, Katayama $\mathrm{S}$ et al (2005) The transcriptional landscape of the mammalian genome. Science 309:15591563

12. Mattick JS (2009) The genetic signatures of noncoding RNAs. PLoS Genet 5:e1000459

13. Consortium EP (2012) An integrated encyclopedia of DNA elements in the human genome. Nature 489:57-74

14. Wang KC, Chang HY (2011) Molecular mechanisms of long noncoding RNAs. Mol Cell 43:904-914

15. Guttman M, Donaghey J, Carey BW et al (2011) lincRNAs act in the circuitry controlling pluripotency and differentiation. Nature 477:295-300

16. Khaitan D, Dinger ME, Mazar J et al (2011) The melanomaupregulated long noncoding RNA SPRY4-IT1 modulates apoptosis and invasion. Cancer Res 71:3852-3862

17. Ginger MR, Shore AN, Contreras A et al (2006) A noncoding RNA is a potential marker of cell fate during mammary gland development. Proc Natl Acad Sci U S A 103:5781-5786

18. Paralkar VR, Weiss MJ (2011) A new 'Linc' between noncoding RNAs and blood development. Genes Dev 25:2555-2558

19. Tripathi V, Ellis JD, Shen Z et al (2010) The nuclear-retained noncoding RNA MALAT1 regulates alternative splicing by modulating SR splicing factor phosphorylation. Mol Cell 39:925-938

20. Wapinski O, Chang HY (2011) Long noncoding RNAs and human disease. Trends Cell Biol 21:354-361

21. Batista PJ, Chang HY (2013) Long noncoding RNAs: cellular address codes in development and disease. Cell 152:1298-1307

22. Debussche X, Lormeau B, Boitard C, Toublanc M, Assan R (1994) Course of pancreatic beta cell destruction in prediabetic NOD mice: a histomorphometric evaluation. Diabetes Metab 20:282-290 
23. Gotoh M, Maki T, Satomi S et al (1987) Reproducible high yield of rat islets by stationary in vitro digestion following pancreatic ductal or portal venous collagenase injection. Transplantation 43:725-730

24. Lilla V, Webb G, Rickenbach K et al (2003) Differential gene expression in well-regulated and dysregulated pancreatic beta-cell (MIN6) sublines. Endocrinology 144:1368-1379

25. Marr RA, Rockenstein E, Mukherjee A et al (2003) Neprilysin gene transfer reduces human amyloid pathology in transgenic mice. J Neurosci 23:1992-1996

26. Moore F, Naamane N, Colli ML et al (2011) STAT1 is a master regulator of pancreatic $\beta$-cell apoptosis and islet inflammation. J Biol Chem 286:929-941

27. Wolden-Kirk H, Rondas D, Bugliani M et al (2014) Discovery of molecular pathways mediating 1,25-dihydroxyvitamin D3 protection against cytokine-induced inflammation and damage of human and male mouse islets of Langerhans. Endocrinology 155:736-747

28. Carrero JA, Calderon B, Towfic F, Artyomov MN, Unanue ER (2013) Defining the transcriptional and cellular landscape of type 1 diabetes in the NOD mouse. PLoS One 8:e59701

29. Norlin S, Ahlgren U, Edlund H (2005) Nuclear factor-\{kappa $\}$ B activity in $\beta$-cells is required for glucose-stimulated insulin secretion. Diabetes 54:125-132

30. Cardozo AK, Heimberg H, Heremans Y et al (2001) A comprehensive analysis of cytokine-induced and nuclear factorkappa B-dependent genes in primary rat pancreatic beta cells. J Biol Chem 276:48879-48886

31. Ortis F, Pirot P, Naamane $\mathrm{N}$ et al (2008) Induction of nuclear factorkappaB and its downstream genes by TNF-alpha and IL-1beta has a pro-apoptotic role in pancreatic beta cells. Diabetologia 51: $1213-1225$

32. Ortis F, Cardozo AK, Crispim D, Storling J, Mandrup-Poulsen T, Eizirik DL (2006) Cytokine-induced proapoptotic gene expression in insulin-producing cells is related to rapid, sustained, and nonoscillatory nuclear factor-kappaB activation. Mol Endocrinol 20:1867-1879

33. Kurrer MO, Pakala SV, Hanson HL, Katz JD (1997) Beta cell apoptosis in T cell-mediated autoimmune diabetes. Proc Natl Acad Sci U S A 94:213-218

34. O'Brien BA, Harmon BV, Cameron DP, Allan DJ (1997) Apoptosis is the mode of beta-cell death responsible for the development of IDDM in the nonobese diabetic (NOD) mouse. Diabetes 46:750-757

35. Derrien T, Johnson R, Bussotti G et al (2012) The GENCODE v7 catalog of human long noncoding RNAs: analysis of their gene structure, evolution, and expression. Genome Res 22:1775-1789
36. Ravasi T, Suzuki H, Pang KC et al (2006) Experimental validation of the regulated expression of large numbers of non-coding RNAs from the mouse genome. Genome Res 16:11-19

37. Ize-Ludlow D, Lightfoot YL, Parker M et al (2011) Progressive erosion of beta-cell function precedes the onset of hyperglycemia in the NOD mouse model of type 1 diabetes. Diabetes 60:2086-2091

38. Eizirik DL, Mandrup-Poulsen T (2001) A choice of death - the signal-transduction of immune-mediated beta-cell apoptosis. Diabetologia 44:2115-2133

39. Gurzov EN, Eizirik DL (2011) Bcl-2 proteins in diabetes: mitochondrial pathways of beta-cell death and dysfunction. Trends Cell Biol 21:424-431

40. Eizirik DL, Cardozo AK, Cnop M (2008) The role for endoplasmic reticulum stress in diabetes mellitus. Endocr Rev 29:42-61

41. Hayden MS, Ghosh S (2004) Signaling to NF-kappaB. Genes Dev 18:2195-2224

42. Giannoukakis N, Rudert WA, Trucco M, Robbins PD (2000) Protection of human islets from the effects of interleukin-1beta by adenoviral gene transfer of an Ikappa B repressor. J Biol Chem 275: 36509-36513

43. Heimberg H, Heremans Y, Jobin C et al (2001) Inhibition of cytokine-induced NF-kappaB activation by adenovirus-mediated expression of a NF-kappaB super-repressor prevents beta-cell apoptosis. Diabetes 50:2219-2224

44. Eldor R, Yeffet A, Baum K et al (2006) Conditional and specific NF-kappaB blockade protects pancreatic beta cells from diabetogenic agents. Proc Natl Acad Sci U S A 103:5072-5077

45. Gough DJ, Levy DE, Johnstone RW, Clarke CJ (2008) IFNgamma signaling-does it mean JAK-STAT? Cytokine Growth Factor Rev 19:383-394

46. Lin Y, Jamison S, Lin W (2012) Interferon-gamma activates nuclear factor-kappa B in oligodendrocytes through a process mediated by the unfolded protein response. PLoS One 7:e36408

47. Rimbach G, Valacchi G, Canali R, Virgili F (2000) Macrophages stimulated with IFN-gamma activate NF-kappa B and induce MCP1 gene expression in primary human endothelial cells. Mol Cell Biol Res Commun 3:238-242

48. Ku GM, Kim H, Vaughn IW et al (2012) Research resource: RNASeq reveals unique features of the pancreatic beta-cell transcriptome. Mol Endocrinol 26:1783-1792

49. Cabili MN, Trapnell C, Goff L et al (2011) Integrative annotation of human large intergenic noncoding RNAs reveals global properties and specific subclasses. Genes Dev 25:1915-1927 